Provided for non-commercial research and education use. Not for reproduction, distribution or commercial use.

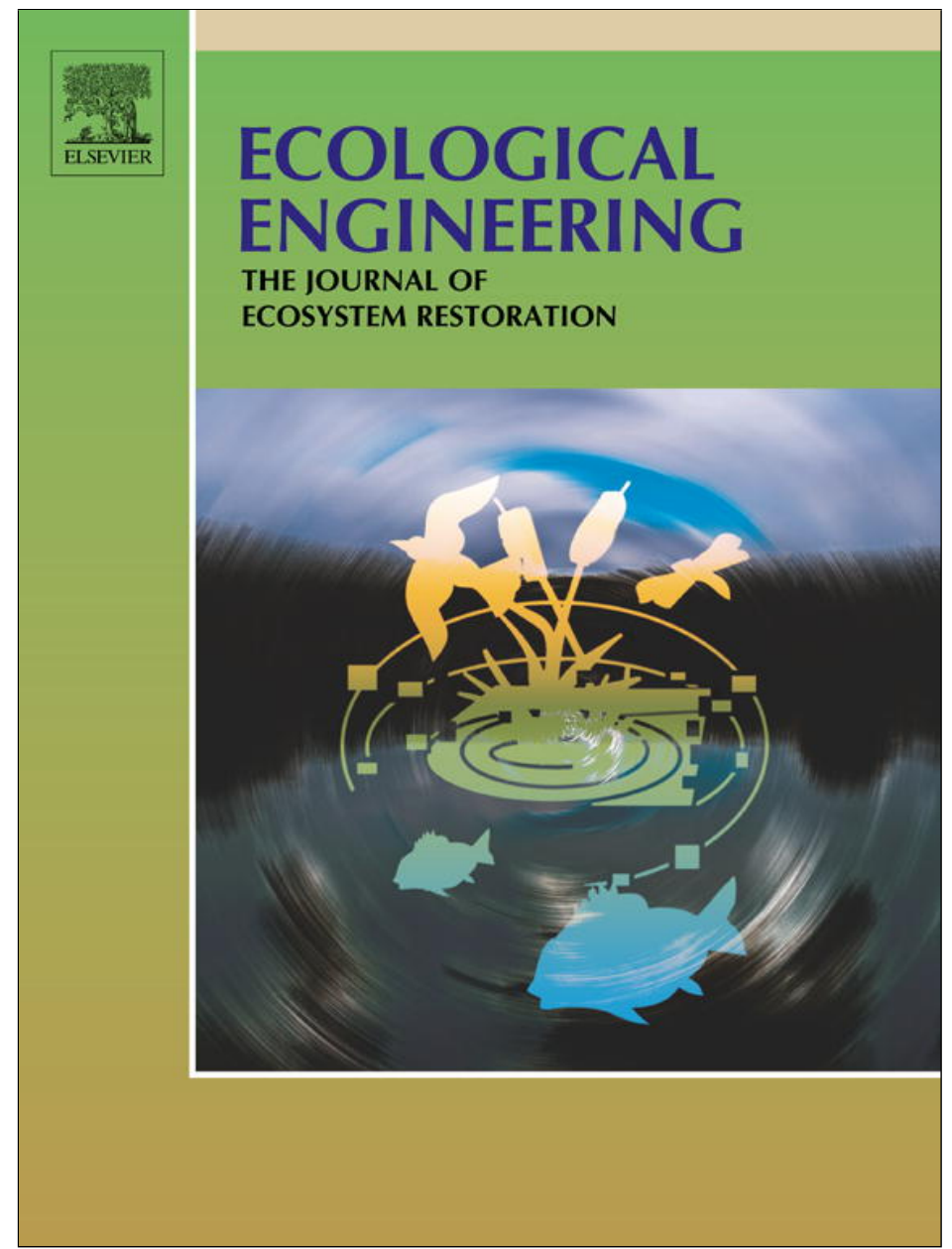

(This is a sample cover image for this issue. The actual cover is not yet available at this time.)

This article appeared in a journal published by Elsevier. The attached copy is furnished to the author for internal non-commercial research and education use, including for instruction at the authors institution and sharing with colleagues.

Other uses, including reproduction and distribution, or selling or licensing copies, or posting to personal, institutional or third party websites are prohibited.

In most cases authors are permitted to post their version of the article (e.g. in Word or Tex form) to their personal website or institutional repository. Authors requiring further information regarding Elsevier's archiving and manuscript policies are encouraged to visit:

http://www.elsevier.com/copyright 


\title{
Long term outdoor operation of a tubular airlift pilot photobioreactor and a high rate algal pond as tertiary treatment of urban wastewater
}

\author{
Zouhayr Arbib a,*, Jesús Ruiza , Pablo Álvarez-Díaz a , Carmen Garrido-Pérez ${ }^{a}$, Jesus Barragana,b, \\ José A. Perales ${ }^{a}$
}

a Department of Environmental Technologies, Centro Andaluz de Ciencia y Tecnología Marinas (CACYTMAR), Campus de Excelencia Internacional del Mar (CEIMAR), Campus Universitario de Puerto Real, University of Cádiz, 11510 Puerto Real, Cádiz, Spain

b Chiclana Natural S. A. M., Chiclana de la Frontera, Cádiz, Spain

\section{A R T I C L E I N F O}

\section{Article history:}

Received 9 October 2012

Received in revised form

10 December 2012

Accepted 11 December 2012

\section{Keywords:}

Wastewater

High rate algal pond

Tubular photobiorteactor

Nutrient removal

Scenedesmus obliquus

\begin{abstract}
A B S T R A C T
$530 \mathrm{~L}$ high rate alga pond (HRAP) and $380 \mathrm{~L}$ airlift tubular photobioreactor (TPBR) were operated and compared in a urban wastewater treatment plant (WWTP), with the main purpose of removing nitrogen and phosphorous from the effluent of the WWTP while generating a valuable biomass. The photosynthetic activity in TPBR was during entire experiment higher than HRAP. The maximum areal productivity reached was $8.26 \pm 1.43$ and $21.76 \pm 0.3 \mathrm{~g} \mathrm{SS} \mathrm{m}^{-2} \mathrm{~d}^{-1}$ for HRAP and TPBR respectively. Total nitrogen (TN) removal averaged $89.68 \pm 3.12$ and $65.12 \pm 2.87 \%$ for TPBR and HRAP respectively, while for total phosphorus (TP) TPBR and HRAP averaged $86.71 \pm 0.61$ and $58.78 \pm 1.17 \%$ respectively. The lipid content showed no significant differences $(p<0.05)$ between HRAP and TPBR averaging $20.80 \pm 0.22 \mathrm{wt} \%$. The main operating disadvantage of TPBR versus HRAP was the sever biofouling which forced to stop the experiment. Under the same conditions of operation TPBR was more limited at low temperatures than HRAP, and HRAP was more light limited than TPBR.
\end{abstract}

(c) 2013 Elsevier B.V. All rights reserved.

\section{Introduction}

Secondary effluents from conventional wastewater treatment plants (WWTP) still containing high concentration of nutrients (nitrogen and phosphorus), which have been identified as the main causes leading to eutrophication in natural waters bodies (RuizMarin et al., 2010). Therefore, prior to discharging the effluent they must receive suitable treatment. It has been widely studied that algae can grow satisfactorily in nitrogen and phosphorus rich conditions, which are common conditions to many wastewaters (Ruiz et al., 2011; Arbib et al., 2012). This aspect can be exploited not only to remove these nutrients from the wastewater, but also to the simultaneous production of valuable algae biomass, as well as a carbon dioxide biofixation technology that can reduce the carbon footprint of the whole wastewater treatment process.

Successful simultaneous nutrient removal, biomass generation and carbon dioxide biofixation require careful growth bioreactor design. Algal culture systems are generally classified in open and closed systems (Tredici, 2004).

\footnotetext{
* Corresponding author. Tel.: +34 956016781; fax: +34 956016746.

E-mail address: zouhayr.arbib@uca.es (Z. Arbib).
}

The use of open ponds as a method for the cultivation of microalgae is quite common, in use since the 1950s (Oswald et al., 1957; Dodd, 1986). Open Raceways or high rate algal pond (HRAP) are open shallow ponds with a paddle wheel to provide circulation of algae and nutrients. One of the major advantages of HRAP is that they are easier to construct and operate than most closed systems, and they are also relatively cheap to build and operate. However, major limitations in HRAP include: (1) poor light utilization by the cells due to the poor mixing (dark zones) and to the large light path $(20-45 \mathrm{~cm})$, which result in low productivity; (2) contamination by predators and other fast growing heterotrophs; (3) high evaporative losses; (4) high diffusion of $\mathrm{CO}_{2}$ to the atmosphere; (5) requirement of large areas of land; and (6) high cost associated to the harvesting, due to the low biomass concentration achieved (less that $0.5 \mathrm{~g} \mathrm{~L}^{-1}$ ) (Mata et al., 2010); in practice, productivities of even $10-20 \mathrm{~g} \mathrm{~m}^{-2} \mathrm{~d}^{-1}$ are difficult to achieve in HRAP (Shen et al., 2009).

Most closed systems have been developed to maximize the surface/volume ratio. Common materials used for closed systems include glass, Plexiglas, poly vinyl chloride (PVC) and Polyethylene. Tubular photobioreactor (TPBR) consist of an array of straight glass or plastic tubes also called solar receiver that captures sun light efficiently. TPBR can be divided according to Tredici (2004) in four main categories: (1) serpentine TPBR. (2) 
manifold TPBR, (3) helicoidal TPBR and finally (4) fence arrangement with manifolds. Algae cultures are recirculated either with a mechanical pump or airlift system. The latter have several advantages such as allowing $\mathrm{CO}_{2}$ and $\mathrm{O}_{2}$ to be exchanged between the liquid medium and aeration gas as well as providing a low shear stress recirculation system (Sánchez-Mirón et al., 2003).

In comparison to HRAP, TPBR can promote much higher photosynthetic efficiency, thanks to the smaller light path and to the well controlled conditions of operation. But TPBR also has several disadvantages: (1) the excessive supply of radiant energy to narrow TPBR may lead to photon loss or even photoinhibition, this problem could be solved by using a large diameter TPBR coupled with the maintenance of high turbulent flow inside the solar receiver; (2) toxic accumulation of $\mathrm{O}_{2}$, which could cause inhibition of photosynthesis; (3) overheating, temperature inside TPBR can be $10-15^{\circ} \mathrm{C}$ higher than in ambient (4) biofouling accumulation on the surface of the solar receiver and (5) high initial investment costs (Mata et al., 2010)

For an effective simultaneous biomass generation and nutrient removal, the biomass generated must be efficiently removed from the broth. Efficient algal biomass harvest (removal) is essential to achieve high quality wastewater treatment and cost-effective production. One of the major bottlenecks, limiting the development of most microalgae biomass production system, is the cost-effective of harvesting, contributing to $20-30 \%$ to the total cost of production (Molina-Grima et al., 2003). Recovery of biomass can be a significant problem, on the one hand because of the small size of the algal cells (3-30 $\mu$ m diameter); and on the other hand, because culture broth is generally relatively dilute d (less than $0.5 \mathrm{~g} \mathrm{~L}^{-1}$ for open systems and around $1.5 \mathrm{~g} \mathrm{~L}^{-1}$ for closed systems). Methods of biomass recovery include filtration, centrifugation, sedimentation, flocculation and floatation. According to Molina-Grima et al. (2004) harvesting of algal cells by flocculation is more convenient than by conventional methods such as centrifugation or filtration, because it allows large quantities of culture to be treated. Chemical flocculation has become the method of choice in removal of algae from waste treatment ponds and other waste applications. Flocculation by adding Multivalent metal salts such as aluminum sulfate $\left(\mathrm{Al}_{2}\left(\mathrm{SO}_{4}\right)_{3}\right.$, alum) have been widely used to flocculate algal biomass in wastewater treatment processes (Franceschi et al., 2002). According to different authors (Papazi et al., 2010) Aluminium salts are usually more effective than iron salts, making them useful for the recovery of Scenedesmus or Chlorella.

Comparison of performance achieved by HRAP and TPBR may not be easy and few reliable comparisons between closed and open systems are available in the literature (Molinuevo-Salces et al., 2010). The evaluation depends on several factors such as: geographic locations, culture strategies (batch or continuous culture), algae species etc. Therefore the main objective of this study was to simultaneously operate and compare at pilot plant scale the performance of a $380 \mathrm{~L}$ TBPR and $533 \mathrm{~L}$ HRAP located in a WWTP, with the main objective of treating the effluent as a tertiary treatment for nutrient removal while enhancing algae biomass generation.

\section{Material and methods}

\subsection{Microorganism}

The microalga strain used in this study was Scenedesmus obliquus (SAG 276-10) (S. obliquus), obtained from the Culture Collection of Algae (SAG), Göttingen University (Germany). Inoculum for the experiments was cultivated in non strilezed urban wastewater at $20 \pm 1^{\circ} \mathrm{C}$. A set of 6 fluorescent lamps ( 3 Sylvania Gro-Lux F57W and 3 Philips TLD 58W) providing $250 \mu \mathrm{mol} \mathrm{cm}^{-2} \mathrm{~s}^{-1}$ were used as light source, under $14: 10 \mathrm{~h}$ light dark cycle.

\subsection{Culture media}

The culture medium used was a secondarily pre-treated wastewater from the WWTP located in Arcos de la Frontera $\left(36^{\circ} 44^{\prime} 56.56^{\prime \prime} \mathrm{N}, 5^{\circ} 47^{\prime} 37.12^{\prime \prime} \mathrm{W}\right.$, Spain). The feedstock was collected daily after the preliminary screening, primary sedimentation, activated sludge and secondary sedimentation processes. Table 1 shows the average nutrient composition of the influent wastewater during the different periods of the continuous mode operation in both photobioreactors.

\subsection{Photobioreactors}

The experimental set up consisted of two different cultivation systems: an open system or high rate algal pond (HRAP) (Fig. 1A and $B$ ) and a closed system or airlift tubular photobioreactor (TPBR) (Fig. 1C and D).

The HRAP was constructed in fiberglass, with a total working volume of 533 liters operating at $300 \mathrm{~mm}$ depth, with a surface of $1.93 \mathrm{~m}^{2}$ (2525 mm length, $750 \mathrm{~mm}$ width and $450 \mathrm{~mm}$ depth) (Fig. $1 \mathrm{~A}$ and $\mathrm{B}$ ). The surface to volume ratio $(S / V)$ was equal to 3.62 . The culture was mixed mechanically with a paddle wheel with 4 blades by a motor engine at $5 \mathrm{rpm}$, reaching a flow velocity between 0.2 and $0.3 \mathrm{~cm} \mathrm{~s}^{-1}$. The paddle wheel sits in a depression (sump) on the pond bottom, this sump serves to reduce the back flow (Dodd, 1986). Also, eccentrically placed curved walls were assembled at the end of the furthest away from the paddle wheel. This created curve zones of accelerating flow, followed by a flow expansion zone after the directional changes (Dodd, 1986).

TPBR (Fig. 1C and D) was designed and constructed according to the recommendations of Pirt et al. (1983) and Molina-Grima et al. (2001). TPBR was divided in two parts, firstly a solar receiver, which consist in 12 straight transparent polymethylmethacralate (PMMA) tube (external diameter of $110 \mathrm{~mm}$ and internal diameter of $104 \mathrm{~mm}$ ). The length of each tube was $2000 \mathrm{~mm}$. Straight tubes were joined into a vertical loop configuration, also called fence type configuration. The connection between the upper and lower tube was made by means of two $90^{\circ} \mathrm{PVC}$ bends joined by $300 \mathrm{~mm}$ length PMMA tube. The working volume of the solar loop receiver was 330 liters. And secondly an airlift driven system (ADS) was used to recirculate the culture through the solar receiver at low shear stress and strip the excess of oxygen from the broth. ADS (Fig. 1B) was formed by three main sections: riser, downcomer and degasser.

Table 1

Mean average nutrient composition of the influent wastewater during the different periods of the continuous mode. Total nitrogen (TN; mg $\mathrm{L}^{-1}$ ); Total phosphorus (TP; $\mathrm{mg} \mathrm{L}^{-1}$ ); Chemical oxygen demand (COD; $\mathrm{mg} \mathrm{O}_{2} \mathrm{~L}^{-1}$ ); Nitrogen: phosphorus ratio ( $\mathrm{N}: \mathrm{P} ; \mathrm{mol} \mathrm{N}$ mol $\mathrm{P}^{-1}$ ). In period I, II, III and IV.

\begin{tabular}{lrrr}
\hline Parameter & \multicolumn{1}{c}{ P I } & \multicolumn{1}{c}{ P II } & \multicolumn{1}{c}{ PIII } \\
\hline TP $\left(\mathrm{mg} \mathrm{L}^{-1}\right)$ & $1.77 \pm 0.10$ & $2.23 \pm 0.12$ & $2.10 \pm 0.12$ \\
TN $\left(\mathrm{mg} \mathrm{L}^{-1}\right)$ & $26.16 \pm 1.90$ & $25.00 \pm 1.80$ & $2.03 \pm 0.17$ \\
$\mathrm{~N}: \mathrm{P}\left(\mathrm{mol} \mathrm{N} \mathrm{mol} \mathrm{P}^{-1}\right)$ & $32.76 \pm 2.64$ & $24.81 \pm 1.77$ & 2.66 \\
$\mathrm{COD}\left(\mathrm{mg} \mathrm{O}_{2} \mathrm{~L}^{-1}\right)$ & $76.63 \pm 6.30$ & $83.33 \pm 3.21$ & $26.50 \pm 1.80$ \\
\hline
\end{tabular}



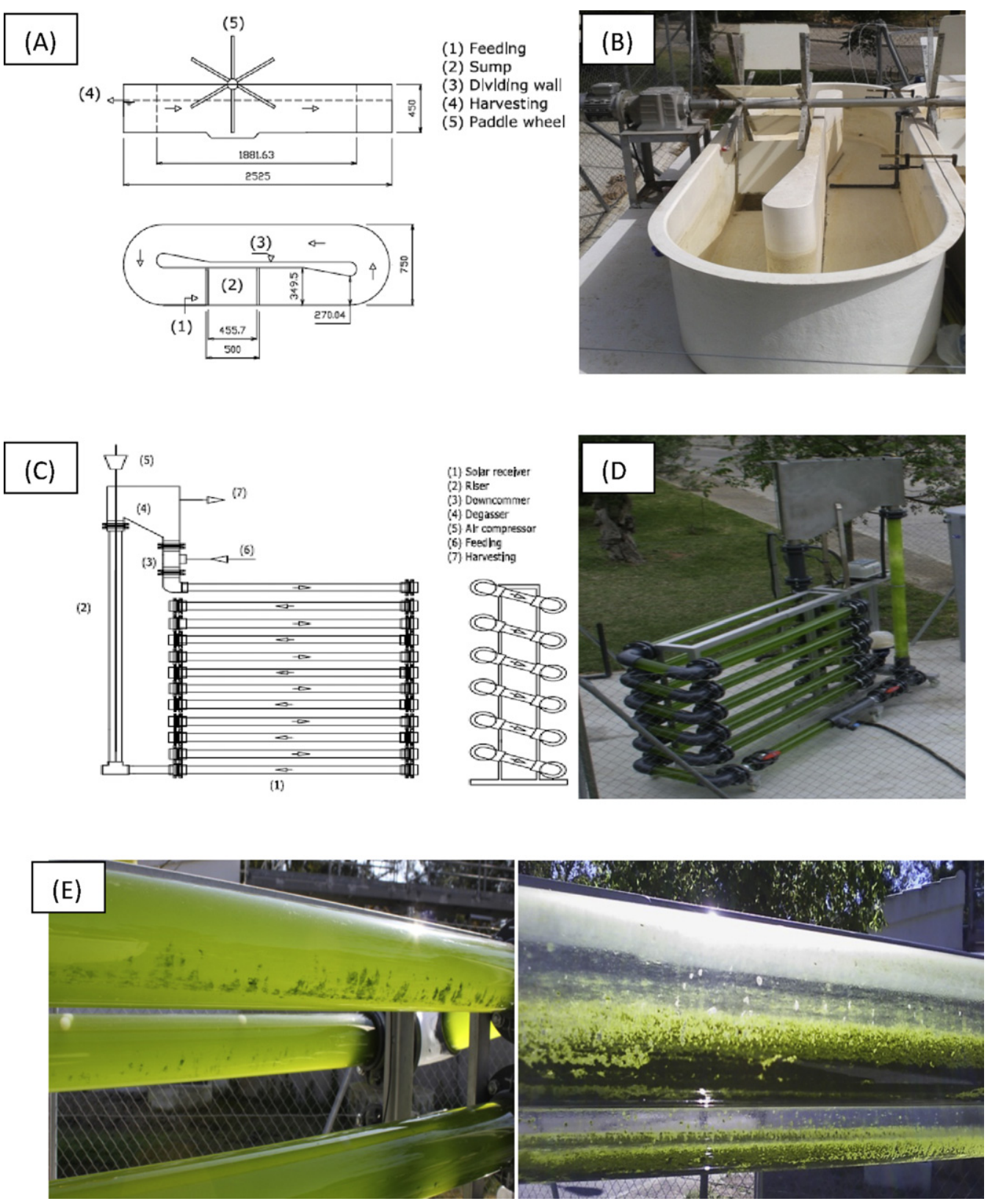

Fig. 1. (A) Flow diagram of the high rate algal pond (HRAP); (B) real HRAP employed in this work;(C) flow diagram of airlift tubular photobioreactor (TPBR); (D) real TPBR employed in this work. (E) Biofouling in TPBR. Left picture: initial appear of biofouling (day 140); right picture: biofouling at the end of the experiment (157 day).

The riser was connected vertically to the end of the loop of the solar receiver by a $90^{\circ} \mathrm{PVC}$ bend. As it was also constructed with a $110 \mathrm{~mm}$ i.d. PMMA tube, it can be considered part of the solar receiver (total volume solar receiver 350 liters). Air was injected at the bottom of the riser, so bubbling promotes culture mixing, degassing and circulation through the solar receiver. The downcomer was joined vertically by $90^{\circ} \mathrm{PVC}$ bends to the beginning of the solar receiver. The gas-liquid separator (degasser) was connected to the riser and the downcomer, being the bottom of the degasser slanted to avoid the sedimentation of the solids (MolinaGrima et al., 2001). The total height of the ADS was $3000 \mathrm{~mm}$. The total working volume of the dark zone (degasser + downcomer) was $30 \mathrm{~L}$, which, in accordance to the recommendations of Molina-Grima et al. (2001), was less than $12 \%$ of the total volume.

\subsection{Experimental design}

TPBR and HRAP were operated in the WWTP of Arcos de la Frontera at a extreme climatic conditions for the region, from 24th October 2011 to 29th March 2012 (157 days) with the main objective of treating the effluent of the wastewater as tertiary treatment (nitrogen and phosphorus removal below the most restrictive limits of the European Directive (1998) 98/15/EC) while generating a valuable microalgae biomass. Both photobioreactors (PBR's) were filled with wastewater and inoculated with S. obliquus, inoclulation was made to obtain an initialconcentration in each photobioreactor between 100 and $120 \mathrm{mg} \mathrm{L}^{-1}$ (inoculums $10 \%$ of total working volume for each PBR). Firstly PBR's were operated in batch mode, with the aim of obtaining the most appropriate dilution rate or hydraulic retention time (HRT) to be applied, according to the 
(A)
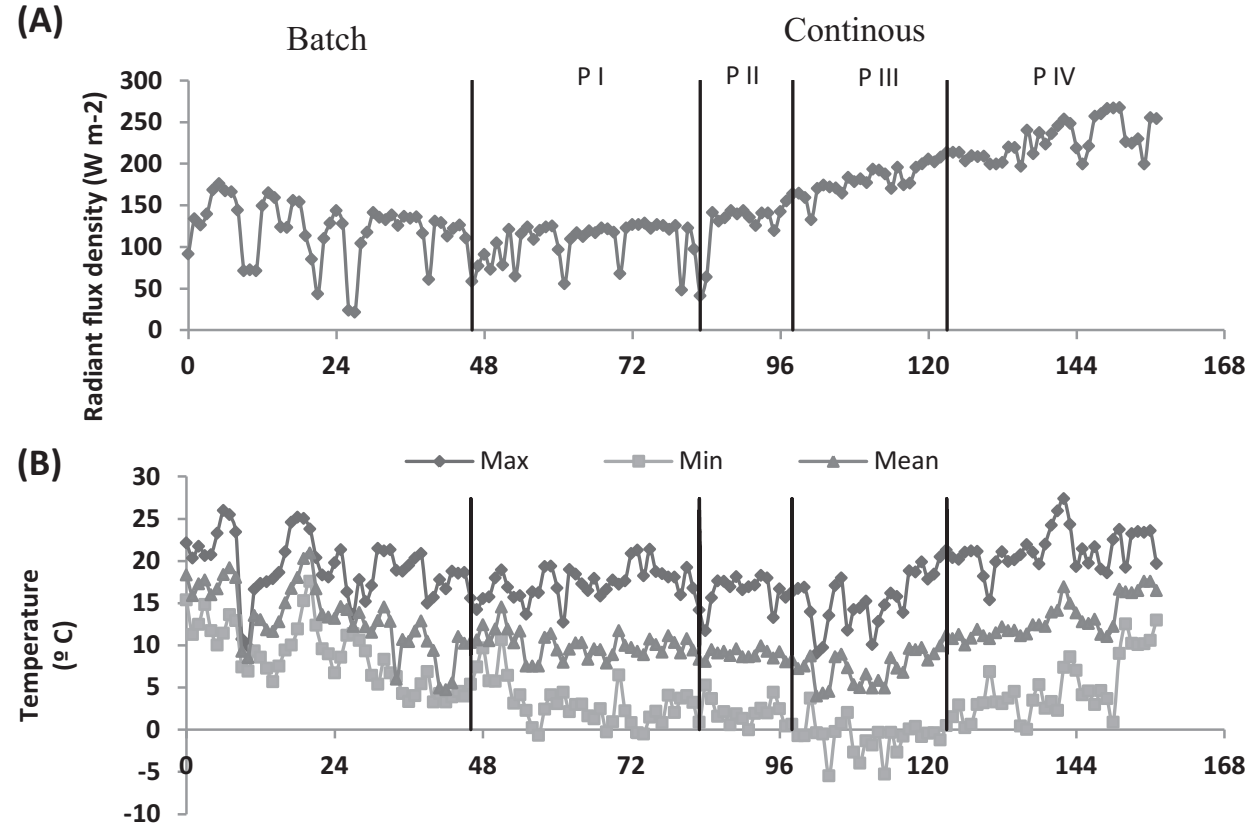

(C)

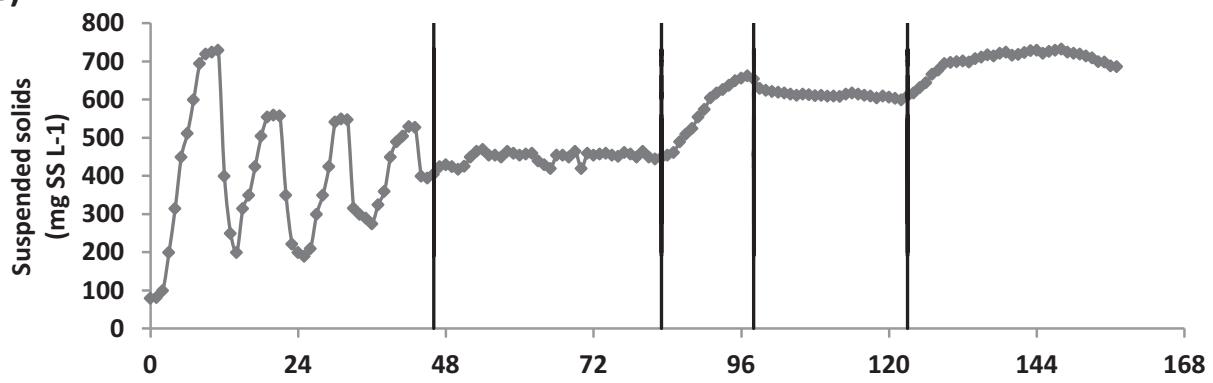

(D)

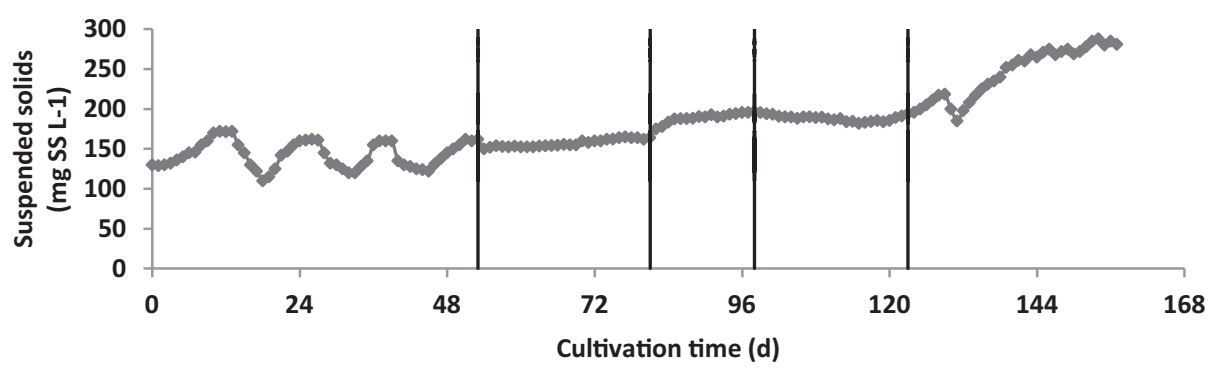

Fig. 2. (A) Time course evolution of Radiant flux density $\left(\mathrm{W} \mathrm{m}^{-2}\right)$; (B) maximum, minimum and mean temperature $\left({ }^{\circ} \mathrm{C}\right)$; (C) time course of biomass concentration as suspended solids ( $\mathrm{mg} \mathrm{SS} \mathrm{L}^{-1}$ ) in the airlif tubular photobioreactor (TPBR) and (D) time course of biomass concentration as suspended solids (mg SS L ${ }^{-1}$ ) High Rate Algal Pond (HRAP).

climatic conditions and characteristics of the fresh medium (nitrogen and phosphorus concentration). The procedure in both cases was similar: operating in batch mode until the stationary phase was reached (biomass increase lower than 1\% per day during 3 consecutive days). After that, feeding pumps were connected at a certain flow to achieve the appropriate HRT. When the biomass concentration decreased during the following days (at least 3 days) that mean HRT applied was below wash-out retention time, so the feeding pumps were stopped until a new stationary phase was reached. Then, a higher HRT was applied in continuous mode. Once the proper HRT was achieved for each reactor, both PBR's were operated in continuous mode (for 110 days. During the continuous mode the Pilot plant were fed during the light period only were the photosynthetic take place (Rebolloso-Fuentes et al., 1999). Daily in batch and in continuous mode, and in both photobioreactors the evaporation rate was compensated with the addition of tap water.

\subsection{Analytical procedure}

Biomass dry weight as suspended solids, was determined gravimetrically according to Standard Methods (APHA, AWWA, WPCF, 2008).

Liquid samples for nutrient consumption analysis were withdrawn three days a week from each PBR. Total nitrogen (TN) and total phosphorus (TP) were determined, based on the method proposed by Köthe and Bitsch (1992), mixing $10 \mathrm{~mL}$ of the sample and 
1.5 micro spoon of OXISOLV ${ }^{\circledR}$ (Merck KGaA, Darmstadt, Germany), then incubated at $100^{\circ} \mathrm{C}$ for $60 \mathrm{~min}$ and then cooled to room temperature. Once samples were completely oxidized, nitrate determinations were performed according to Spectroquant ${ }^{\circledR}$ test kit (Cod. 1.14773.0001 (Merck), and phosphates were performed according to the ascorbic acid standard method (Ref. 4500-P E; APHA, AWWA, WPCF, 2008). Chemical oxygen demand (COD) was determined according to Standard Methods 5220-D (APHA, AWWA, WPCF, 2008). Based on the changes of the climatic conditions and on the variation of the nutrient concentration of the wastewater (Table 1) four different periods were distinguished in $i$ the continuous mode of operation, and the biomass composition in each period was analyzed for both PBR's. Biomass was harvested by centrifugation (Centrifuge Mixtasel-BL Selecta ${ }^{\circledR}$ ) at $4200 \mathrm{rpm}$ for $10 \mathrm{~min}$. The resulting pellets were rinsed twice with deionized water by resuspending and centrifuging. Algae pellets were dried in a lyophilizer (Labconco, FreeZone Triad Cascade Benchtop). An elementary analysis (percentage of $\mathrm{C}, \mathrm{N}, \mathrm{H}$ and $\mathrm{S}$ ) was performed by a Leco ${ }^{\circledR}$ CHNS 932 analyzer. Biomass lipid concentration was determined in duplicate. Lipids were extracted according to a modified method reported by Takagi et al. (2006) and Wiltshire and Boersma (2000), to $90 \mathrm{mg}$ of lyophilized pellets, $12 \mathrm{~mL}$ of $2: 1$ trichloromethane:methanol and $0.6 \mathrm{~g}$ of analytical grade quartz were added and the mixture was sonicated in a bath $(60 \mathrm{kHz}$; $360 \mathrm{~W}$ ) for $90 \mathrm{~min}$. Extraction was done twice and both extracts were mixed, centrifuged and filtered to ensure quartz separation. Filtrate was evaporated under reduced pressure in a rotary evaporator. The remainder was dried at $100-105^{\circ} \mathrm{C}$ for $12 \mathrm{~h}$ and weighed as total lipids.

\subsection{Flocculation-sedimentation experiments}

Flocculation-sedimentation experiments were performed in $1000 \mathrm{~mL}$ graduated beaker, in a programmable four paddle jar-tester (Flocumatic, Selecta ${ }^{\circledR}$ ). A stock solution was previously prepared by dissolving 10.0 grams of aluminium sulphate, $\mathrm{Al}_{2}\left(\mathrm{SO}_{4}\right)_{3} \cdot 18 \mathrm{H}_{2} \mathrm{O}$ (Panreac ${ }^{\circledR}$ ) into $1000 \mathrm{~mL}$ distilled water. The flocculant dose was added to the harvested volume from each photobioreactor $(1000 \mathrm{~mL})$ under intense stirring at $120 \mathrm{rpm}$ for $2 \mathrm{~min}$ to ensure complete solubility of the coagulant. Following this, the stirring was reduced to gentle agitation at $20 \mathrm{rpm}$ for $30 \mathrm{~min}$, so as to favor flocs formation. At the end of the $30 \mathrm{~min}$ the stirrers were turned off to allow the settling during $20 \mathrm{~min}$. After this, the optical density at $750 \mathrm{~nm}$ (turbidity) of the clarified zone and the harvested sample was determined. Samples were taken in the clarified volume. Biomass removal efficiency (BRE) was calculated by measuring optical density and using the following equation 1 (Andrea et al., 2012).

$\mathrm{RE}=\left(1-\mathrm{OD}_{\mathrm{f}} / \mathrm{OD}_{\mathrm{i}}\right) * 100$

where, $\mathrm{OD}_{\mathrm{f}}$ is the optical density after 20 min settling and $\mathrm{OD}_{\mathrm{i}}$ is the initial optical density at time zero of the harvested sample.

\section{Results and discussion}

\subsection{Start-up and general performance}

The performance of microalgae cultivation reactors depends mainly on the climatic conditions of the location (Azov and Shelef, 1982), as solar radiance and temperatures affect directly the algae photosynthetic activity and therefore their productivity (Lundquist et al., 2009). Therefore, the radiant flux density (RFD; $\mathrm{W} \mathrm{m}^{-2}$ ) and the maximum, minimum and mean ambient temperature $\left({ }^{\circ} \mathrm{C}\right)$ during the entire experiment were monitored (Fig. 2A and B).
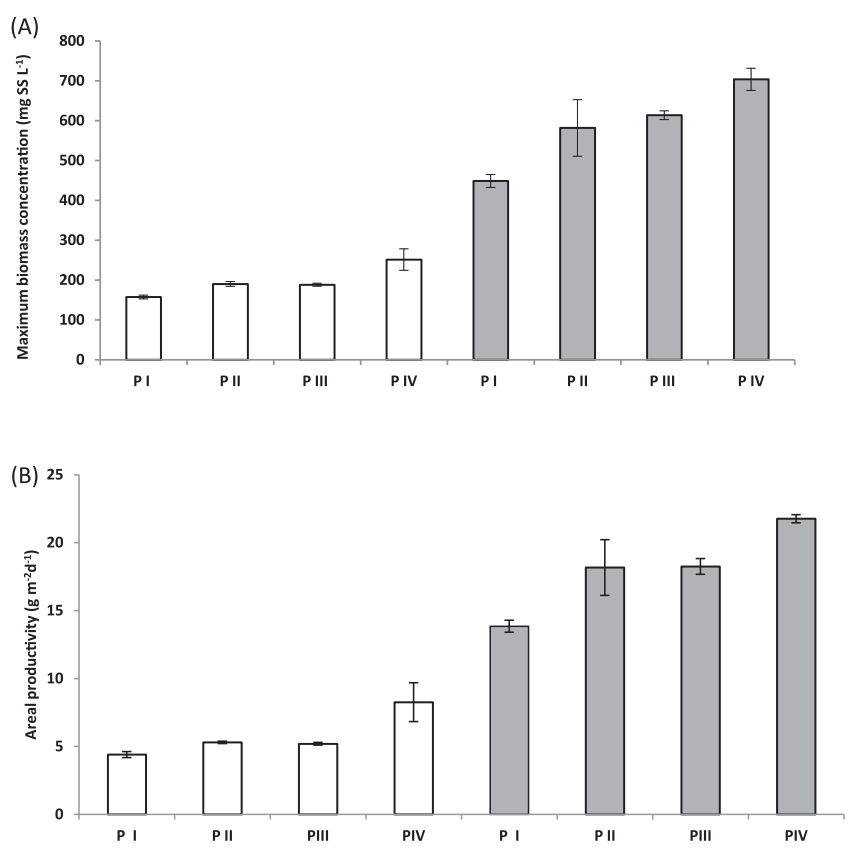

Fig. 3. (A) Maximum biomass concentration $\left(\mathrm{mg} \mathrm{L}^{-1}\right)$ and (B) areal productivity $\left(\mathrm{g} \mathrm{m}^{-2} \mathrm{~d}^{-1}\right)$ in continuous mode (CM) achieved in HRAP (white box) and TPBR (grey box) at the different periods.

Biomass evolution ( $\mathrm{mg} \mathrm{L}^{-1}$ ) of TPBR and HRAP were plotted in Fig. 3A and B. In both PBR's, two different operational conditions were conducted: an initial period in which the PBR's were operated in batch mode (batch mode) in order to obtain growth kinetics parameters, and secondly the continuous mode.

Batch mode comprises the experiment from the beginning until day 45 for TPBR and day 53 for HRAP. The main objective of this period was to achieve the proper HRT to be applied. In the case of TPBR four different HRT were tested until the optimum was reached $(2,3,4$ and 5 days), and for HRAP also four different HRT were tested (7, 8, 9 and 10 days). There were great differences between HRT applied for each PBR. The reason of that is that HRAP was more light limited than TPBR (a light path of $300 \mathrm{~mm}$ compared to $110 \mathrm{~mm}$ of TPBR), and therefore the growth rate in TPBR was faster than HRAP.

Once the proper HRT was applied for each pilot plant, 5 days of hydraulic retention time for TPBR and 10 days for HRAP, the Pilot plant were operated in continuous mode until the end of the experiment (Fig. 2C and D).

During continuous mode, 4 different periods (almost the same for both PBR's) named I, II, III and IV, were clearly differentiated (Fig. 2C and D).

Period I comprises day 46 to 83 for TPBR and day 54 to 83 for HRAP. The biomass concentration in these periods remains constant in both PBR's, being higher in TPBR than HRAP, with an average of $448.74 \pm 16.17$ and $157.55 \pm 4.86 \mathrm{mg} \mathrm{SS} \mathrm{L}^{-1}$ respectively (Fig. 3A). Despite the fact that HRT in HRAP was 2-folds higher than TPBR, there were great and significant differences between the biomass concentrations achieved. This confirms the greater light limiting of the HRAP. The stability of the biomass concentration in both PBR's was due to the non changes of the climatic conditions (Fig. 2A and B) and nutrient concentration (Table 1) during period I.

Period II, comprises day 84 to 98 for both pilot plant (Fig. 2C and D). During this period there were no significant differences in temperature with regards to period I (Fig. 2B), and RFD showed a slight increment regarding period I, from $110.80 \pm 24.35$ to $135.19 \pm 22.33 \mathrm{Wm}^{-2}$ (Fig. 2A), but 

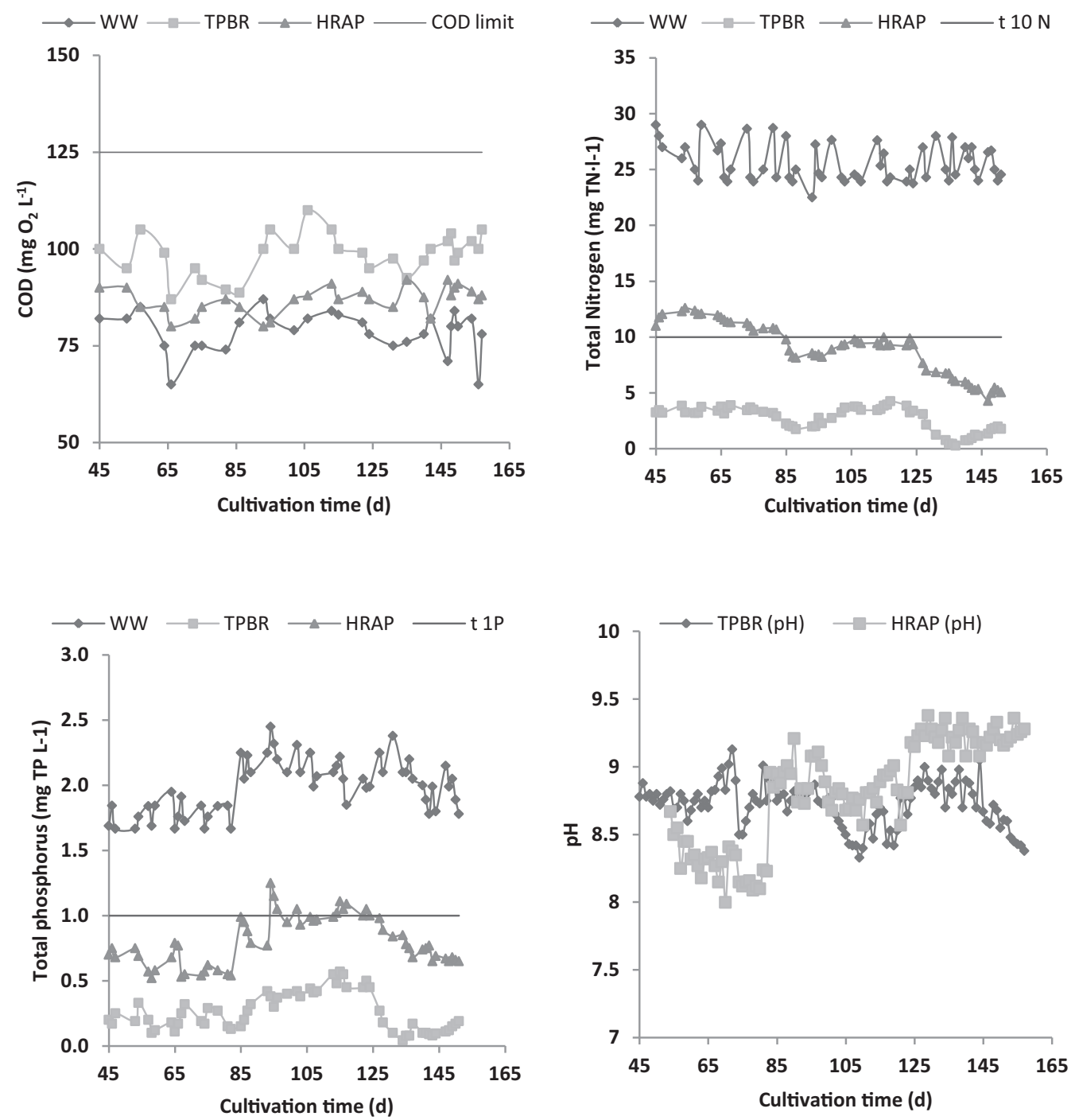

Fig. 4. Time course of nutrient in tubular photobioreactor (TPBR) and in high rate algal pond (HRAP) during the continuous mode operation: (A) total soluble chemical oxygen demand ( $\left.\mathrm{mg} \mathrm{O}_{2} \mathrm{~L}^{-1}\right)$; (B) total nitrogen ( $\left.\mathrm{mg} \mathrm{L}^{-1}\right)$; (C) total phosphorus ( $\left.\mathrm{mg} \mathrm{L}^{-1}\right)$ : and (D) time course pH evolution of High rate algal pond (HRAP) and the Airlift tubular photobioreactor (TPBR).

this difference was not significant. Despite all that, biomass in both pilot plant showed an increment with regard to period I, from $157.55 \pm 4.86$ to $190.36 \pm 6 \mathrm{mg} \mathrm{SS} \mathrm{L}^{-1}$ for HRAP, and from $448 \pm 74.2$ to $581.55 \pm 70.53 \mathrm{mg} \mathrm{SS} \mathrm{L}^{-1}$ for TPBR (Fig. 3A). This similar biomass augmentation in both PBR's (21\% and 30\% for HRAP and TPBR respectively) cannot be attributed only to the slight increase of the RFD, but also to an enhancement of the phosphorus concentration in the influent wastewater during period II against period I (Table 1). A similar increase observed for biomass concentration was also determined for average concentration of phosphorus between period I $\left(1.77 \pm 0.09 \mathrm{mg} \mathrm{P}^{\left.-\mathrm{PO}_{4} \mathrm{~L}^{-1}\right)}\right.$

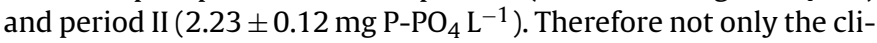
matic condition affects the biomass evolution, but also the variation of the nutrient concentration of the influent. Further details about nutrient influence are considered in the next section.

In period III, which comprises day 99 to 123 , an increase in the RFD has been observed, from $135.19 \pm 22.33 \mathrm{~W} \mathrm{~m}^{-2}$ (PII) to $182.64 \pm 16.26 \mathrm{~W} \mathrm{~m}^{-2}$ (PIII) (Fig. 2A), and there were no significant variations in the nutrient concentration (Table 1) (Nitrogen and phosphorus). According to the RFD increase, biomass concentration should continue growing as in PII. However, biomass concentration showed a slightly decrease in TPBR, from $650 \mathrm{mg} \mathrm{SS} \mathrm{L}^{-1}$ to $600 \mathrm{mg} \mathrm{SS} \mathrm{L}^{-1}$ at the end of period III. In HRAP, biomass concentration remained almost constant during all the period (188.45 $\pm 3.70 \mathrm{mg} \mathrm{SS} \mathrm{L}^{-1}$ ) (Fig. 3A). This inhibition of the growth in both PBR's can be attributed to the extreme low temperatures reached at night during period III, which presented significant differences regarding the previous period II. The average minimum temperature in period III was $-1.10 \pm 1.25^{\circ} \mathrm{C}$ while in period II was $2.076 \pm 1.49$, and the minimum reached were -5.45 and $0.00^{\circ} \mathrm{C}$ for period III and II respectively. This phenomenon was also reported by Lundquist et al. (2009). They determined that in the majority deserted regions of the United States of America the limiting factor in algae growth would be the low temperatures at night.

Finally period IV comprised the last 34 days of operation (25th February to 29th March). During this period the average maximum, minimum and mean temperature were $21.37 \pm 2.4^{\circ} \mathrm{C}$, $4.65 \pm 3.34{ }^{\circ} \mathrm{C}$ and $13.03 \pm 2.25^{\circ} \mathrm{C}$ respectively (Fig. $2 \mathrm{~B}$ ), and the RFD was the highest in all the cultivation time $\left(227.33 \pm 23.26 \mathrm{~W} \mathrm{~m}^{-2}\right)$ (Fig. 2A). TPBR and HRAP showed in this period a different behaviour. At the beginning of period IV the biomass concentration 
in TPBR increased and the maximum of all tests were reached in this period at day 148 of cultivation $\left(733 \mathrm{mg} \mathrm{SS} \mathrm{L}^{-1}\right)$. From this point, biomass density began to stabilize and even at the end of the trial began to decrease. This decrease in biomass could be due to fouling phenomena (Fig. 1E), which began to appear on day 140 of cultivation. At the end of the test the presence of biofouling was highly significant, occupying around $30-35 \%$ of the total surface of the solar receiver. Biofouling prevents penetration of solar radiation and therefore limits the photosynthesis activity and the growth rate. Moreover, a significant fraction of the generated biomass forms this biofouling, so it was not included as suspended biomass in the effluent.

HRAP showed the maximum growth in period IV (Fig. 2D). At the beginning of the period the biomass concentration showed an exponential growth phase. From day 124 to 130 the biomass concentrations increased from 195.78 to $218.56 \mathrm{mg} \mathrm{SS} \mathrm{L}^{-1}$ (Fig. 2D). At this point, the HRT was decreased from 10 to 8 days. Initially, the biomass concentration suffered a drop during the first two days operating at 8 days of HRT, but after that the biomass started to increase again, reaching finally an average final biomass concentration of $245.45 \pm 32.40 \mathrm{mg} \mathrm{SS} \mathrm{L}^{-1}$. This increase in biomass concentration seems to be related to the climatic conditions and mainly to the increase of RFD (Fig. 2A) as nutrient concentration did not show significant differences respect to the previous period III (Table 1$)$. Regarding the areal productivity $\left(P_{\mathrm{a}} ; \mathrm{gSS} \mathrm{m}^{-2} \mathrm{~d}^{-1}\right)$, significant differences between TPBR and HRAP can be clearly appreciated (Fig. 3B), ranging between 2.5 and 3.5-folds higher in TPBR than in HRAP depending of the period of operation. It is noteworthy that the lowest differences between them were reached in period IV, where HRAP was less light limited due to the increase in RFD. The maximum $P_{\mathrm{a}}$ reached for HRAPS was $8.26 \pm 1.43$ and for TPBR was $21.76 \pm 0.3 \mathrm{~g} \mathrm{SS} \mathrm{m}^{-2} \mathrm{~d}^{-1}$. In a previous work, Torzillo et al. (1986) also found significant differences in both Spirulina platensis and maxima when cultivated simultaneously in outdoor closed photobioreactor and in an open raceway, reporting a mean areal productivity of 25 and $15 \mathrm{~g} \mathrm{SS} \mathrm{m}^{-2} \mathrm{~d}^{-1}$ for the closed PBR and open system respectively. In this case the differences between both technologies were lower than in our study. However, it should be kept in mind that the results for HRAP in our study were obtained during extreme climatic conditions (November-March), while Torzillo et al. (1986) results were obtained during the month of maximum photosynthetic activity (July).

Maximum $P_{\mathrm{a}}$ obtained for HRAP seems to be lower if it is compared to data proposed for different authors (Raven, 1988; Ben-Amotz, 1980). These authors predicted a maximum yield of 135 to $346 \mathrm{~g} \mathrm{SS} \mathrm{m}^{-2} \mathrm{~d}^{-1}$ for long term operation of open systems. Becker (1994) considered these predictions unrealistic, and one tenth of them would be considered in a normal range, between 13.5 and $34.6 \mathrm{~g} \mathrm{SS} \mathrm{m}^{-2} \mathrm{~d}^{-1}$. According to that, Tredici (2004) also reported that long term productivity of a well managed open ponds rarely exceeds $12-13 \mathrm{~g} \mathrm{SS} \mathrm{m}^{-2} \mathrm{~d}^{-1}$, and during shorts periods in experimental algal ponds may achieve $20-25 \mathrm{~g} \mathrm{SS} \mathrm{m}^{-2} \mathrm{~d}^{-1}$. To make a realistic comparison, two works were chosen because of the similar culturing media used (wastewater), to the location (both in Spain) and to the dimensions of the HRAP used. Firstly De-Godos et al. (2010) operated two HRAP at 10 days HRT treating diluted swine manure (dilution was made to get a $400 \mathrm{mg} \mathrm{O}_{2} \mathrm{~L}^{-1} \mathrm{COD}$ ), they reported an average $P_{\mathrm{a}}$ between $9.2 \pm 1.4$ and $10.7 \pm 1.86 \mathrm{~g} \mathrm{VSS} \mathrm{m}^{-2} \mathrm{~d}^{-1}$. Secondly, García et al. (2006) operated two HRAP at 8 and 10 days of HRT, treating an influent settled urban wastewater, they reported a monthly average $P_{\mathrm{a}}$ of $9 \pm 3 \mathrm{gTSS} \mathrm{m}^{-2} \mathrm{~d}^{-1}$ operating at 10 days HRT, and $9.75 \pm 3.49 \mathrm{~g} \mathrm{TSS}^{-2} \mathrm{~d}^{-1}$ at 8 days HRT. These results are in accordance with those proposed by the present study.
Another interesting work to compare our results with, is the one proposed by Jiménez et al. (2003). They extrapolated an annual dry weight biomass production rate of 30 tonnes per hectare per year of Spirulina sp. (in synthetic medium) using a $450 \mathrm{~m}^{2}$ and $0.30 \mathrm{~m}$ deep raceway pond system, achieving a $P_{\mathrm{a}}$ of $8.2 \mathrm{~g} \mathrm{~m}^{-2} \mathrm{~d}^{-1}$ in Malaga $\left(36^{\circ} 42 \mathrm{~N}, 4^{\circ} 28 \mathrm{~W}\right.$.) (Southern Spain). The climatic conditions were nearly the same as in our work. Is important to note that although the culture medium and the species of microalgae are different, the final productivities obtained in both works were similar, something that indicates the great importance of the climatic conditions.

\subsection{Nutrient removal}

Total nitrogen (TN), total phosphorus (TP) and chemical oxygen demand (COD) in the influent wastewater are presented in Table 1. TN and COD were the parameters with less variation during all the experimental period. The average TN and COD in the continuous mode were $25.43 \pm 0.54 \mathrm{mg} \mathrm{L}^{-1}$ and $79.62 \pm 3.17 \mathrm{mg} \mathrm{O}_{2} \mathrm{~L}^{-1}$ respectively. On the other hand, TP presented significant differences between period I and the other periods (II, III and IV), being lower in period I. These variations of TP affect the N:P molar ratio of the influent WW, which varies between $24.81 \pm 1.77$ to $32.76 \pm 2.64$. This variation can affect greatly the biomass generation and the nutrient removal capability of the microalgae (Arbib et al., 2012; Xin et al., 2010). As it was analyzed in Section 3.1, an increment of the biomass concentration in both PBR's was observed between period I and II, which can be partially attributed to this TP concentration increment (Table 1 ).

Fig. 4A-C showed COD, TN and TP evolution during the continuous operation period in the influent wastewater and in the effluent of both PBR's.

COD concentrations in TPBR and HRAP effluent were higher than in the influent wastewater (Fig. 4A). This could be due to the low biodegradability of the organic matter of the WWTP. This low biodegradability could lead to a carbon limitation of the algae growth, which in turn explains the high pH values (Fig. 4D) reached in both PBR's. The average $\mathrm{pH}$ in HRAP and TPBR during the entire continuous mode were $9.32 \pm 0.30$ and $8.72 \pm 0.16$ respectively. TPBR seems to be less carbon limited than HRAP, perhaps due to the inorganic carbon dioxide added indirectly in the airlift pump. COD was higher in TPBR effluent during all continuous mode period than in HRAP probably due to the higher shear stress of the airlift pump than the paddle wheels. It is important to note that although the COD increased, the regulated limit of discharge (Directive $98 / 15 / \mathrm{CE})$ was not reached $\left(125 \mathrm{mg} \mathrm{O}_{2} \mathrm{~L}^{-1}\right)$.

TN removal efficiency (TNRE) during all the continuous mode period was higher in TPBR than in HRAP, being significant the differences during all periods (Table 2). The average of the entire continuous mode was $89.68 \pm 3.12$ and $65.12 \pm 2.87 \%$ for TPBR and HRAP respectively. And as can be observed in Fig. 4B, TN concentration in TPBR effluent was below the most restrictive limit of discharge of the European directive (1998) 98/15/CE (10 $\mathrm{mg} \mathrm{N} \mathrm{L}^{-1}$ ) during all periods, average effluent concentration of $2.61 \pm 1.09 \mathrm{mg} \mathrm{TNL}^{-1}$ in TPBR. On the other hand, HRAP was unable to produce an effluent with TN concentration below $10 \mathrm{mg} \mathrm{N} \mathrm{L}^{-1}$ during the first 81 days of continuous mode operation (Period I) possibly due to the low photosynthetic activity reached at this period (period with the lowest biomass productivity, $\left.4.4 \mathrm{~g} \mathrm{SS} \mathrm{m}^{-2} \mathrm{~d}^{-1}\right)$.

Between periods I, II and IV TPBR showed no significant differences in TNRE $(91.07 \pm 0.31 \%)$. A slight decrease in TNRE was observed in period III $(85.53 \pm 1.9 \%)$, presenting significant differences against periods II and IV, at period III an inhibition of biomass growth was observed due to the low temperatures. This reduction of TNRE at period III could also be appreciated in HRAP, but in this 
Table 2

Total nitrogen (TN), total phosphorus (TP) and soluble chemical oxygen demand (SCOD) removal efficiency (RE, \%) in the four periods (PI, PII, PIII and PIV) of the continuous mode operation for both plant; Relationship between the inlet nutrient mass flow and the mass of microalgae in the reactor (N:M ratio).

\begin{tabular}{|c|c|c|c|c|c|c|c|c|}
\hline \multirow[t]{2}{*}{ Parameter } & \multicolumn{4}{|l|}{ HRAP } & \multicolumn{4}{|l|}{ TPBR } \\
\hline & PI & P II & PIII & P IV & P I & P II & PIII & P IV \\
\hline RE TN (\%) & $55.7 \pm 3.5$ & $65.6 \pm 2.2$ & $62.1 \pm 2.2$ & $77.02 \pm 3.5$ & $86.8 \pm 1.3$ & $91.4 \pm 1.3$ & $85.5 \pm 2.0$ & $94.9 \pm 2.9$ \\
\hline RE TP (\%) & $64.3 \pm 5.9$ & $56.25 \pm 6.1$ & $51.4 \pm 4.0$ & $63.2 \pm 4.0$ & $88.7 \pm 3.9$ & $86.5 \pm 3.9$ & $77.8 \pm 3.03$ & $94.0 \pm 2.7$ \\
\hline RE SCOD (\%) & -12.02 & 1.44 & -8.65 & -14.26 & -24.68 & -17.5 & -25.04 & -29.43 \\
\hline $\mathrm{N}: \mathrm{M}\left(\mathrm{Kg} \mathrm{N} \mathrm{Kg} \mathrm{SS}^{-1} \mathrm{~d}^{-1}\right)$ & 0.0167 & 0.0132 & 0.0131 & 0.0128 & 0.0117 & 0.0086 & 0.0081 & 0.0073 \\
\hline
\end{tabular}

case the differences with period II are not significant, due to the lowest growth inhibition observed in period III for HRAP.

In HRAP, TNRE increased as the photosynthetic activity increased itself, reaching the maximum at period IV (77.02 $\pm 3.52 \%)$ and the minimum at period I $(55.73 \pm 2.53 \%)$. The highest TNRE achieved in the last period cannot be attributed only to the biomass uptake, because biomass production in period IV $\left(8.26 \pm 1.43 \mathrm{~g} \mathrm{SS} \mathrm{m}^{-2} \mathrm{~d}^{-1}\right)$ was not enough to achieve such a high TNRE $(77.02 \pm 3.52 \%)$ by biological assimilation. Therefore, it could be considered that ammonium stripping could have played an important role in TNRE during this period, due mainly to the high $\mathrm{pH}$ achieved in period IV $(9.69 \pm 0.133)$ (Nurdogan and Oswald, 1995).
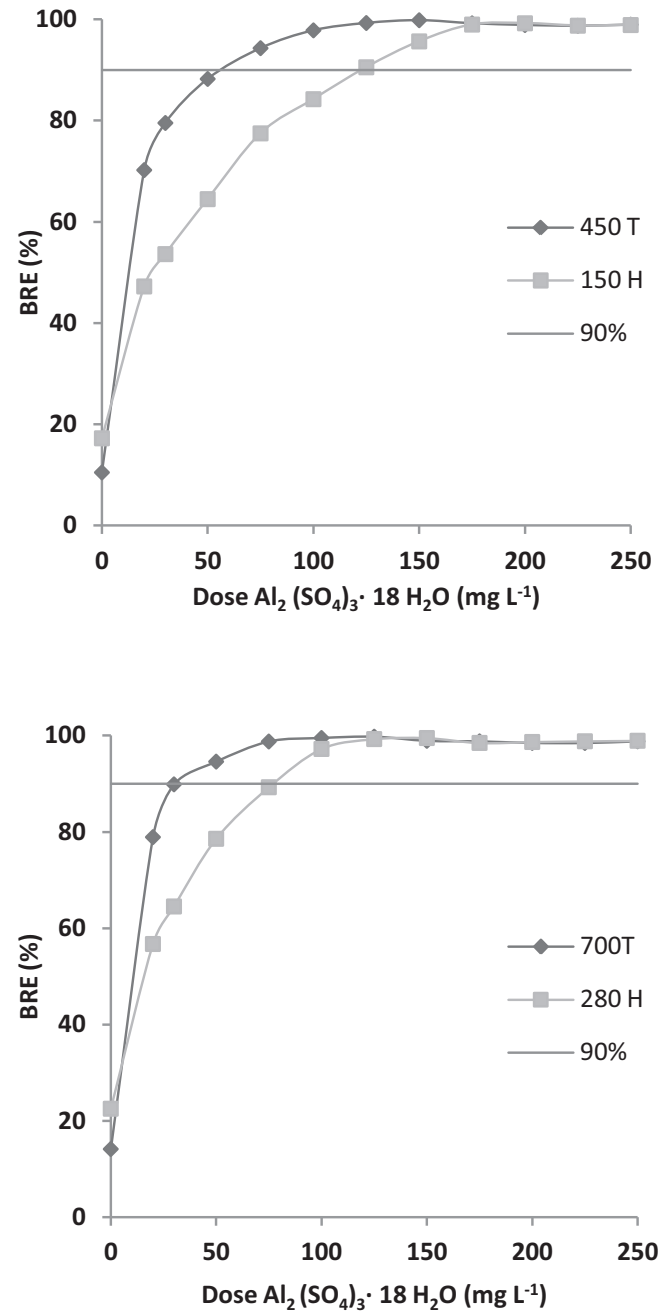

In Fig. 4C, TP concentrations in the influent wastewater as well as in both PBR's effluents are presented. It can be observed that TP effluent concentrations were below $1 \mathrm{mg} \mathrm{L}^{-1}$ during all continuous mode period in both PBR's, except for HRAP effluent between experimental days 94 and 128 approximately (Periods II and III). In TPBR the TP removal can be mainly attributed to the biotic assimilation, since in TPBR the $\mathrm{pH}$ during all continuous mode was not sufficient to promote the abiotic mechanisms, averaging a $\mathrm{pH}$ of $8.59 \pm 0.047$ (Fig. 4D). While HRAP combines both the abiotic and the biotic mechanisms, averaging $\mathrm{pH}$ during all continuous mode of $9.32 \pm 0.30$ (Fig. 4D) was enough to promote both mechanisms (Nurdogan and Oswald, 1995).
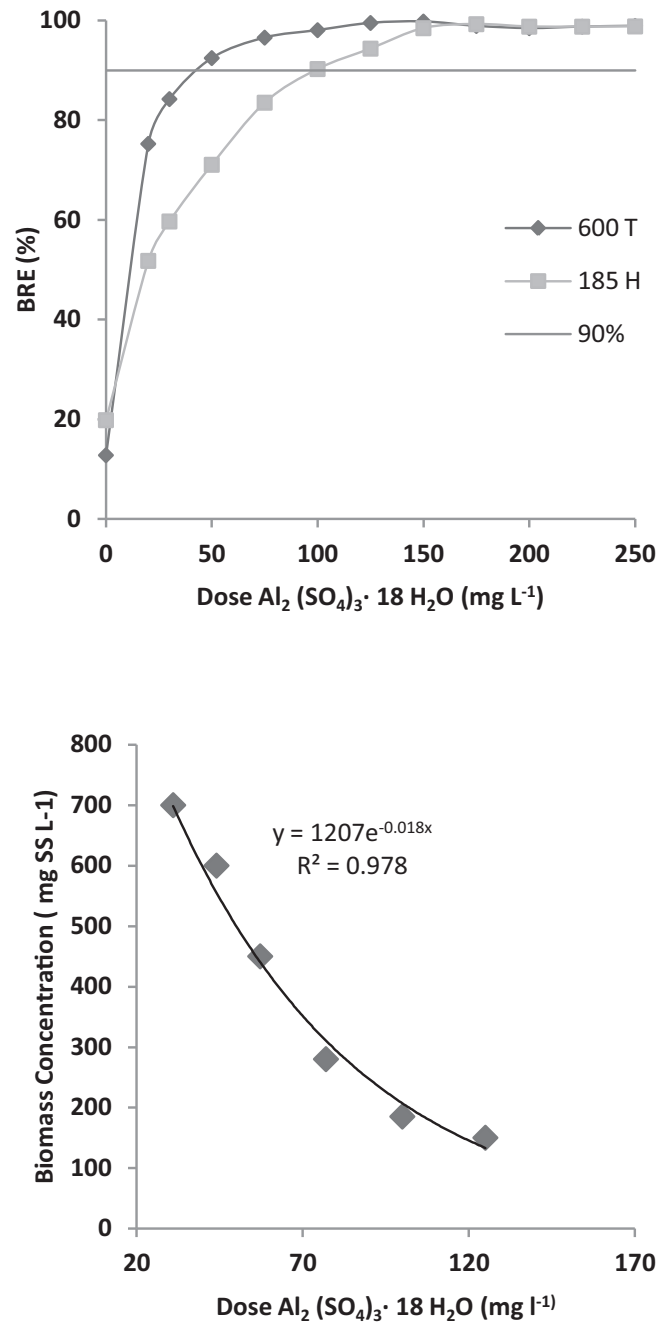

Fig. 5. Effect of microalgae cell concentration and $\mathrm{Al}_{2}\left(\mathrm{SO}_{4}\right)_{3} \cdot 18 \mathrm{H}_{2} \mathrm{O}$ dosage on biomass recovery efficiency (BRE) of Scenedesmus obliquus cultivated in a high rate algal pond (HRAP) and in an airlift tubular photobioreactor (TPBR). (A) $450 \mathrm{mg} \mathrm{SS} \mathrm{L}^{-1}$ (TPBR) and $150 \mathrm{mg} \mathrm{SS} \mathrm{L}^{-1}$ (HRAP); (B) $600 \mathrm{mg} \mathrm{SS} \mathrm{L}^{-1}$ (TPBR) and $185 \mathrm{mg} \mathrm{SS} \mathrm{L}^{-1}$ (HRAP) and (C) $700 \mathrm{mg} \mathrm{SS} \mathrm{L}^{-1}$ (TPBR) and $280 \mathrm{mg} \mathrm{SS} \mathrm{L}^{-1}$ (HRAP): (D) correlation between the biomass concentration ( $\mathrm{mg} \mathrm{SS} \mathrm{L}^{-1}$ ) and the dose of $\mathrm{Al}_{2}\left(\mathrm{SO}_{4}\right)_{3} \cdot 18 \mathrm{H}_{2} \mathrm{O}_{\text {to be }}$ applied (mg L ${ }^{-1}$ ). 

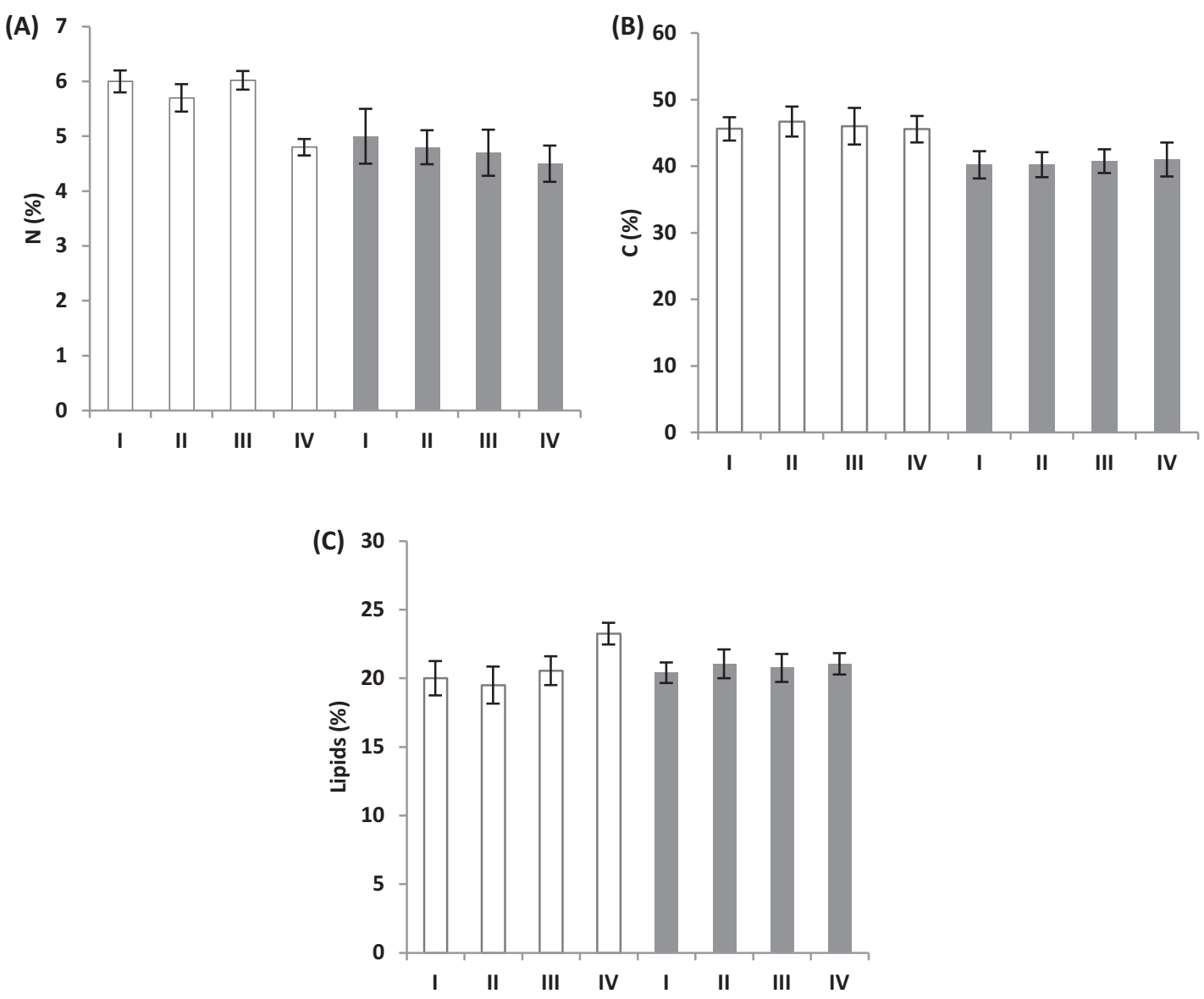

Fig. 6. Biomass composition in tubular photobioreacotr (TPBR) (white) and in high rate algal pond (HRAP) (grey) in the four periods of continuous mode of operation. (A) Nitrogen content (\% dry weight); (B) carbon content (\% dry weight); (C) lipid content (\% dry weight).

Special interest requires the variation of the TP influent concentration between period I and II (Table 1). TPRE in TPBR showed no significant differences between both periods $(88.73 \pm 3.90$ and $86.54 \pm 3.92 \%$ for period I and II respectively). This could indicate that TPBR was in period I probably limited in phosphorus, and therefore when the TP concentration increased in period II the removal efficiency remained constant and the biomass concentration experimented also an increment (Fig. 3A). On the other hand, HRAP showed a significant decrease in TPRE between period I and II, from $64.29 \pm 5.94$ to $56.25 \pm 3.60 \%$, this could imply that HRAP was not limited in phosphorus as it was TPBR. Hence, the biomass increment observed in HRAP during period II cannot be attributed to the phosphorous increment in the influent, but perhaps to the RFD enhancement observed during this period (Fig. 2A), which would confirm the more light limitation of HRAP than TPBR.

TPBR was more stable regarding to TPRE and TNRE if compared to HRAP during all the continuous mode operation. TP and TN concentration in the effluent of the TPBR were below the most restrictive limits of the European Directive (1998) (98/15/CE) during the entire continuous mode, while HRAP only reached both limits simultaneously at the end of the experiment (period III). The only disadvantage of TPBR regarding HRAP was that both TPRE and TNRE decreased when the temperatures were extreme at period III (Table 2). TNRE decreased from $91.4 \pm 1.3$ to $86.5 \pm 3.9 \%$ and TPRE from $86.5 \pm 3.9$ to $77.8 \pm 3.03 \%$, while HRAP did not show significant differences in TPRE and TNRE during this period III (Table 2).

\subsection{Flocculation-sedimentation}

The objective of this section was to determine the effect of the cell concentration on the dose of flocculant (Alum) to be applied for an efficient biomass harvesting. As can be observed in Fig. 3A, biomass concentration achieved in HRAP and TPBR were greatly different. Therefore, it is expected that the dose of alum to be applied should be different in both PBR's.

Different doses were tested in order to determine the minimum doses of flocculant necessary to efficiently recover the biomass (recovery efficiency higher than 90\%) at different cell concentrations. When no flocculant was added (control), no interphase was formed. However, slight biomass removal efficiency (BRE) was achieved. In Fig. 5 it can be observed that in all trials, BRE in control was higher in HRAP than in TPBR, despite the fact the biomass concentration in TPBR (450 $\mathrm{mg} \mathrm{L}^{-1}$ ) was 3-folds higher than HRAP ( $\left.150 \mathrm{mg} \mathrm{L}^{-1}\right)$, In the first set, $10.50 \%$ and $17.25 \%$ BRE were achieved in TPBR and HRAP respectively (Fig. 5A); similar results were observed in tests with higher biomass concentrations (Fig. 5B and C). That indicates better settling characteristics of the biomass generated in HRAP than TPBR, due probably to the low stress of the paddle wheels than the airlift system.

As can be seen in Fig. 5, the dose of alum to reach 90\% BRE in TPBR was in all cases lower than in HRAP, related to the great difference in biomass concentration. In both PBR's the flocculant dose to be applied decreases as the biomass concentration increases (Fig. 5). The optimum doses to reach the $90 \%$ of BRE in the different tests were 65,40 and $30 \mathrm{mg} \mathrm{L}^{-1}$ for TPBR and 125,100 and $75 \mathrm{mg} \mathrm{L}^{-1}$ 
for HRAP. Our results are in agreement with data reported by Andrea et al. (2012). The authors reported that an 8-fold cell concentration increase required 6-fold lower $\mathrm{AlCl}_{3}$ dosage, whereas 25 -fold cell concentration increase required 3-fold lower $\mathrm{AlCl} 3$ dosage.

\subsection{Biomass composition}

Fig. 6 shows the biomass composition in TPBR and HRAP in the four phases of the continuous mode of operation.

As can be observed in Fig. 6C, biomass composition in terms of lipid content did not present significant differences between both reactors, averaging $20.8 \pm 0.22 \mathrm{wt} \%$. These results were in agree with those proposed by Mata et al. (2010) and Tang et al. (2011) for Scendesmus sp. Mata et al. (2010) reported a lipid content between 19.6 and 21.1 wt\%, while Tang et al. (2011) ranged between 15.15 and $24.4 \mathrm{wt} \%$. Nevertheless differences can be appreciated in nitrogen and carbon content.

Regarding carbon content (Fig. 6B), no differences between experimental periods were observed for each reactor. When both reactors are compared biomass from TPBR presented higher carbon content, this could be due to the $\mathrm{CO}_{2}$ supplied in the air (almost $0.04 \%$ ) of the airlift system.

In Fig. $6 \mathrm{~A}$ and $\mathrm{C}$ it can be observed that for TPBR, in the last experimental period (IV) the nitrogen and lipid content of the biomass generated was lower and higher respectively, compared with the previously periods. A possible explanation of this could be related with the $\mathrm{N} / \mathrm{M}$ ratio. $\mathrm{N} / \mathrm{M}$ ratio is the relationship between the inlet nutrient mass flow and the mass of microalgae in the reactor. Average values of $\mathrm{N} / \mathrm{M}$ in both reactors in the different experimental periods are presented in Table 2. As can be observed N/M in period IV for TPBR showed the lowest values, this is, in this period the biomass nitrogen availability was lower, which could promote the production of biomass with less nitrogen reserves and a higher lipid content because of the stress.

In Table 2 can be also observed that for all the experimental periods HRAP presented higher N/M values than TBPR. This should implied that biomass generated in HRAP presented higher nitrogen content, nevertheless as can be seen in Fig. 6A this not occurs. This could be because not all the nitrogen in the influent is available for biomass assimilation, as an important part of it is removed by means of abiotic processes (stripping) because of the higher $\mathrm{pH}$ values reached in HRAP, as previously mentioned.

\section{Conclusions}

Soluble nitrogen and phosphorus concentration in the TPBR effluent were during all experiment below the most restrictive limits of discharge of European Directive (1998) $\left(1 \mathrm{mg} \mathrm{L}^{-1} \mathrm{P}\right.$ and $10 \mathrm{mg} \mathrm{L}^{-1} \mathrm{~N}$ ), while HRAP only reached both limits when photosynthetic activity increased. Under the same conditions, the photosynthetic activity of TPBR was between 2- and 2.5-folds higher than HRAP. HRAP was greatly influenced by the radiant flux density, confirming the greater light limitation. TPBR suffered inhibition at low temperatures. The major operating disadvantage of TPBR was severe bioufouling that appeared in TPBR and affected negatively biomass generation and nutrient removal.

\section{Acknowledgements}

This research was supported by the projects CTM2008-01249 financed by the Ministry of Science and Innovation (Spainish Government) and P08-TEP-03854 financed by the Council of
Innovation, Science and Enterprise (Regional Government of Andalusia, Spain)

\section{References}

APHA, AWWA, WPCF, 2008. Standard Methods for the Examination of Water and Wastewater, 22nd ed. American Public Health Association/American Water Work Association/Water Environmental Federation, Washington, DC.

Andrea, J., Garzon-Sanabria, Ryan, T., Davis, Zivko, L., Nikolov, 2012. Harvesting Nannochloris oculata by inorganic electrolyte flocculation. Bioresour. Technol. 118 418-442.

Arbib, Z., Ruiz, J., Alvarez, P., Garrido, C., Barragan, J., Perales, J.A., 2012. Chlorella stigmatophora for urban wastewater nutrient removal and $\mathrm{CO}_{2}$ abatement. Int . Phytorem. 14, 714-725.

Azov, Y., Shelef, G., 1982. Operation of high-rate oxidation ponds: theory and experiments. Water Res. 16, 1153-1160.

Becker, E.W. (Ed.), 1994. Microalgae Biotechnology and Microbiology. Cambridge University Press, Cambridge.

Ben-Amotz, A., 1980. Glycerol production in the algae Dunaliella. In: San Pietro, A (Ed.), Biochemical and Photosynthetic Aspects of Energy Production. Acedemic Press, New York, pp. 191-208.

De-Godos, I., Blanco, S., García-Encina, P., Bécares, E., Muñoz, R., 2010. Influence of flue gas sparging on the performance of high rate algae ponds treating agroindustrial wastewaters. J. Hazard. Mater. 179, 1049-1054.

Dodd, J.C., 1986. Elements of pond design and construction. In: Richmond, A. (Ed.), Handbook of Microalgal Mass Cultures. CRC Press, Inc., Boca Raton, FL, pp. 265-284

European Commision Directive, 1998. 98/15/EC of 27 February. Official Journal of the European Communities.

Franceschi, M., Girou, A., Carro-Diaz, A.M., Maurette, M.T., Puech-Costes, E., 2002. Optimisation of the coagulation-flocculation process of raw water by optimal design method. Water Res. 36, 3561-3572.

García, J., Green, B.F., Lundquist, T., Mujeriego, R., Hernández-Mariné, M., Oswald W.J., 2006. Long term diurnal variations in contaminant removal in high rate ponds treating urban wastewater. Bioresour. Technol. 97, 1709- 1715.

Jiménez, C., Cossío, B.R., Niell, F.X., 2003. Relationship between physicochemical variables and productivity in open ponds for the production of Spirulina: a predictive model of algal yield. Aquaculture 45 (221), 33.

Köthe, J., Bitsch, R., 1992. Oxisolv ${ }^{\circledR}$ plus microwave - a new way for sample pretreatment and sample preparation. Fresenius Journal of Analytical Chemistry. $343,717-718$.

Lundquist, T.J., Woertz, I.C., Quinn, N.W.T., Beneman, J.R., 2009. A Realistic Technology and Engineering Assessment of Algae Biofuel Production. Algae Biofuels Assessment Workshops. Energy Biosciences Institute Berkeley, California January 15-16.

Mata, T.M., Martins, A.A., Caetano, N.S., 2010. Microalgae for biodiesel production and other applications: a review. Renew. Sust. Energy 14, 217- 232.

Molina-Grima, E., Fernández, J., Acién-Fernández, G., Chisti, Y., 2001. Tubular photobioreactor design for algal cultures. J. Biotechnol. 92, 113-131.

Molina-Grima, E., Belarbi, E.H., Acién Fernández, F.G., Robles-Medina, A., Chisti, Y. 2003. Recovery of microalgal biomass and metabolites: process options and economics. Biotechnol. Adv. 20, 491-515.

Molina-Grima, E., Acién-Fernández, F.G., Robles-Medina, A., 2004. Downstream processing of cell-mass and products. In: Amos Richmond (Ed.), Handbook of Microalgal Culture: Biotechnology and Applied Phycology. Blackwell Publishing Ltd., UK, pp. 215-251.

Molinuevo-Salces, B., García-Conzález, M.C., González-Fernandez, C., 2010. Performance comparison of two photobioreactors configurations (open and closed to the atmosphere) treating anaerobically degraded swine manure slurry. Bioresour. Technol. 101, 5144-5149.

Nurdogan, Y. Oswald, W.J., 1995. Enhanced nutrient removal in high rate ponds. Water Sci. Technol. 31, 33-43.

Oswald, W.J., Gotaas, H.B., Golueke, C.G., Kellen, W.R., 1957. Algae in waste treatment. Sewage Ind. Wastes 29, 437-455.

Papazi, A., Makridis, P., Divanach, P., 2010. Harvesting Chlorella minutissima using cellcoagulants. J. Appl. Phycol. 22, 349-355.

Pirt, S.J., Lee, Y.K., Walach, M.R., Watts-Pirt, M., Balyuzi, H.H., Bazin, M.J., 1983. A tubular bioreactor for photosynthetic product of biomass from carbon dioxide: design and performance. J. Chem. Technol. Biotechnol. 33, 35-58.

Raven, J.A., 1988. Limits to growth. In: Borowitzka, M.A., Borowitzka, L.J. (Eds.), Micro-algal Biotechnology. Cambridge University Press, Cambridge, pp. 331-356.

Rebolloso-Fuentes, M.M., García-Sánchez, J.L., Fernandez-Sevilla, J.M., AcienFernandez, F.G., Sanchez-Perez, J.A., Molina-Grima, E., 1999. Outdoor continuous cultura of Porphyridium cruentum in a tubular photobioreactor: quatitative analysis of the daily cyclic variation of cultura parameters. J. Biotechnol. 70 $271-288$

Ruiz, J., Álvarez, P., Arbib, Z., Garrido, C., Barragán, J., Perales, J.A., 2011. Effect of nitrogen and phosphorus concentration on their removal kinetic in treated urban wastewater by Chlorella vulgaris. Int. J. Phytorem. 13, 884-896.

Ruiz-Marin, A., Mendoza-Espinosa, L.G., Stephenson, T., 2010. Growth and nutrient removal in free and immobilized green algae in batch and semi-continuous cultures treating real wastewater. Bioresour. Technol. 101, 58-64. 
Sánchez-Mirón, A., Cerón-García, M.C., Contreras-Gómez, A., García-Camacho, F., Molina-Grima, E., Chisti, Y., 2003. Shear stress tolerance and biochemical characterization of Phaeodactylum tricornutum in quasi steady-state continuous culture in outdoor photobioreactors. Biochem. Eng. J. 16, 287-297.

Shen, Y., Pei, Z.J., Yuan, W.Q., Mao, E., 2009. Effect of nitrogen and extraction method on algae lipid yield. Int. J. Agric. Biol. Eng. 2, 51-57.

Takagi, M., Karseno, Yoshida, T., 2006. Effect of salt concentration on intracellular accumulation of lipids and triacylglyceride in marine microalgae Dunaliella cells. J. Biosci. Bioeng. 101, 223-226.

Tang, D., Han, W., Li, P., Miao, X., Zhong, J., 2011. $\mathrm{CO}_{2}$ biofixation and fatty acid composition of Scenedesmus obliquus and Chlorella pyrenoidosa in response to different $\mathrm{CO}_{2}$ levels. Bioresour. Technol. 102, 3071-3076.
Tredici, M.R., 2004. Mass production of microalgae: photobioreactors. In: Richmond, A. (Ed.), Handbook of Microalgae Culture: Biotechnology and Applied Phycology. Blackwell Publishing, Oxford, pp. 178-214.

Torzillo, G., Pushparaj, B., Bocci, F., Balloni, W., Materassi, R., Florenzano, G., 1986. Production of Spirulina biomass in closed photobioreactors. Biomass 11, 61-74.

Wiltshire, K.H., Boersma, M., et al., 2000. Extraction of pigments and fatty acids from the green alga Scenedesmus obliquus (Chlorophyceae). Aquat. Ecol. 34, 119-126. Xin, L., Hong-Ying, H., Ke, G., Ying-Xsue, S., 2010. Effects of different nitrogen and phosphorus concentrations on the growth, nutrient uptake, and lipid accumulation of a freshwater microalga Scenedesmus sp. Bioresour. Technol. 101, 5494-5500. 